\title{
Patient autonomy and disclosure of material information about hospital-acquired infections
}

This article was published in the following Dove Press journal: Infection and Drug Resistance

\author{
Sorin Hostiuc' \\ Arthur-Jozsef Molnar ${ }^{2}$ \\ Alin Moldoveanu ${ }^{3}$ \\ Maria Aluaș ${ }^{4}$ \\ Florica Moldoveanu ${ }^{3}$ \\ Iuliana Bocicor ${ }^{2}$ \\ Maria-Iuliana Dascalu ${ }^{5}$ \\ Elisabeta Bădilă ${ }^{6}$ \\ Mihaela Hostiuc ${ }^{6}$ \\ lonut $\mathrm{Negoi}^{7}$ \\ 'Department of Legal Medicine and \\ Bioethics, Carol Davila University, \\ ${ }^{2} \mathrm{SC}$ Info World SRL, ${ }^{3}$ Department of \\ Computers, Polytechnic University of \\ Bucharest, Bucharest, ${ }^{4}$ Department \\ of Bioethics, Cluj University of \\ Medicine and Pharmacy, Cluj-Napoca, \\ ${ }^{5}$ Department of Engineering in Foreign \\ Languages, Polytechnic University of \\ Bucharest, ${ }^{6}$ Department of Internal \\ Medicine, ${ }^{7}$ Department of Surgery, \\ Carol Davila University, Bucharest, \\ Romania
}

Correspondence: Sorin Hostiuc

Sos.Vitan Barzesti 9, 042I22 Sector 4

Bucuresti, Romania

Tel +40 723791072

Email soraer@gmail.com

\begin{abstract}
Hospital-acquired infections are nowadays a major health care problem worldwide. The morbidity and mortality associated with them are highest in intensive care units, but their effects are identifiable in virtually any medical department. Information about hospital-acquired infections, especially about their preventive measures, are rarely presented nowadays in a correct fashion to patients. This article aims to present, in a structured manner, the theoretical and practical aspects related to disclosure of hospital-acquired infections-related information to patients and its importance in preventing their spread. We will analyze both the conceptual framework for disclosing medical information related to nosocomial infections (autonomy, veracity, social justice, the principle of double effect, the precautionary principle, and nonmaleficence) and the practicalities regarding the disclosure of proper information to patients.
\end{abstract}

Keywords: informed consent, nosocomial infections, respect for autonomy, social justice, prevention

\section{Introduction}

The prevalence of hospital-acquired infections (HAIs) in Europe ranges from 3.5\% to $10 \%$, with most of them being urinary tract infections, followed by pneumonia, surgery-related infections, and primary sepsis. ${ }^{1}$ The mortality associated with HAI is highest in intensive care units $(10 \%),{ }^{2}$ but is present in virtually all medical departments.

A strategy that could impact the risk of HAIs significantly is the involvement of the patients in prevention and control of the nosocomial infections. ${ }^{3,4}$ Their participation cannot be imagined without a proper disclosure of information related to this issue. Information about HAIs, especially about preventive measures, is rarely presented nowadays in a correct fashion to patients. For example, Merle et al found that $80 \%$ of patients from surgical departments failed to receive information about nosocomial infections. ${ }^{5}$ Martínez Morel et al analyzed the risk of HAIs in informed consent (IC) documents and found that $32 \%$ of all forms for procedures associated with an above-minimal risk of infection did not contain information about this risk; the percentage was higher in IC forms associated with a small risk of infection and lower in those with a higher risk. ${ }^{6}$ Seale et al showed that patients often did not receive any information about either HAIs or infection control. ${ }^{7}$ Again, Merle found that only $17 \%$ of health care workers routinely inform their patients about HAIs; the information usually included: infection control measures, HAI risks associated with an invasive medical procedure, and the consequences of HAIs. Most health care workers, however, 
did not apprise their patients about HAIs, the most often declared reasons being a lack of demand from patients, a lack of specificity about the fact that infections were actually hospital acquired, fear of worrying patients, the belief that patients were not at risk for HAIs, or just the fact that they forget about HAIs during the information procedures. ${ }^{8}$ Even when correct information was given to patients about HAIs, they failed to realize the magnitude of the problem. Newton et al revealed that patients with methicillin-resistant Staphylococcus aureus did not have a clear understanding of what that infection meant and why it is important to take various preventive measures, even if the patients received proper information about these issues. ${ }^{9}$ This article aims to present, in a structured fashion, the theoretical and practical aspects related to disclosure of HAI-related information to patients and its importance in preventing the spread of HAIs.

\section{Theoretical framework for disclosure of HAl-related information}

Usually, when discussing the ethical framework of a certain medical topic, the researchers tend to start by evoking the core principles of medical ethics, such as autonomy, beneficence, nonmaleficence, or justice. However, HAIs are not purely a topic of clinical ethics, as they often have public health consequences, making the approach mentioned above of limited use in practical circumstances. Physicians should not only take measures to minimize the risk of HAI in their patients, but also take proactive measures to limit the transmission of the infectious agents to third parties (other patients, visitors, health care workers, and so on). This may sometimes cause conflicts between the moral requirements of the physicianpatient relationship and those appertaining to public health. For example, if the infection control personnel identify an outbreak, they have to properly identify the source and take measures to limit its spread, even if by doing that the right of the patient to make autonomous choices is altered (can breach the confidentiality of the medical act, the right of free movement of the patient/patients positive for the infectious agent, or even the choice of the patient to refuse a certain medical intervention). Details about these issues were properly systematized elsewhere ${ }^{10-13}$ and are beyond the purpose of this article.

Disclosure of medical information is usually associated with the ethical principles of autonomy and veracity. However, considering the particularities of HAIs, other principles play important roles as well, including nonmaleficence, precautionary principle, the principle of double effect, or social justice.

\section{Autonomy}

A person is considered autonomous if she/he can initiate actions because she/he has the power to initiate them (and therefore is not dependent upon the ability or wish of other persons). The initiation of the action is generated by that person's wish to act, on his/her judgment, and taking into account the potential results and consequences of that action. ${ }^{14}$ Beauchamp and Childress argue that there are two main types of autonomy, person (agent)-based autonomy and action-based autonomy: "The capacity to act autonomously is distinct from acting autonomously, and possession of the capacity is no guarantee that an autonomous choice has been or will be made." 15 Action-based autonomy is respected by letting the patient be in charge regarding the best course of the medical treatment. Disclosure of material information is a mandatory pre-requirement for respecting the autonomy. However, sometimes actions appertaining to patients with HAIs or at risk for HAIs can generate negative, health-related consequences, for other persons. ${ }^{13}$ In these cases, autonomy could be justifiably restricted to minimize the harm done to others. This is the reason for which, for example, some countries instituted mandatory treatment for some infectious diseases such as tuberculosis. This concept was defined by some authors as relational autonomy, which takes into account the social context of the patients, acknowledging the emotional and embodied aspects of decision-making. ${ }^{16}$ Within this concept, the decision-making is shared not only between patients and physicians, but also with other interested parties, such as relatives, or even other patients. Therefore, some limits of the in-control agent autonomy are to be expected within the concept of relational autonomy, and this concept is more appropriate in HAIs than the action-based autonomy that is prevalent in clinical medicine.

The principle of social justice considers that poor health should stay at the cornerstone of public and research policy, and its main aim is to correct the injustice. ${ }^{17,18}$ From a Rawlsian perspective, patients with HAIs have a social disadvantage compared to other patients; however, other patients put at risk by patients with HAIs are also at a social disadvantage compared to the latter, as they risk getting infected. This causes the protection from contagion to become a positive right, which generates the obligation to undertake preventive measure by all relevant parties (including other patients sharing the same ward). Therefore, both the patients with HAIs and those at a high risk (at least) of acquiring HAIs should receive additional safeguards. Patients with HAIs should benefit from specific measures targeted at the removal of the infectious disease, which should always include a full 
disclosure not only about the therapeutic management, but also about nontherapeutic measures aimed at limiting the evolution of the infection. Patients at risk of HAI should not only receive information about preventive measures, but also be the recipients of actions taken by others, aimed at minimizing the spread of nosocomial infections. Such action needs to include specific procedures that should be done not only by health care workers to decrease the spread, but also by other patients, irrespective of their wishes. For example, if a patient has a potentially transmissible airborne disease, and cannot be isolated properly, he could be obliged to wear a mask in the ward. Alternatively, a patient with a Clostridium difficile infection could be compelled to take antibiotics targeting the etiologic agent, or even a fecal microbiota transplant, to minimize the spread of the disease to other patients. Proper information about these issues should be transmitted to all interested parties.

Veracity (or truth-telling) is a mandatory requirement within the physician-patient relationship unless it generates significant harm to the patient, a case in which doctors can conjure the "therapeutic privilege".

The application of therapeutic privilege in clinical practice is a highly cultural phenomenon - some countries see autonomy as an absolute moral value, pricing it over the other fundamental ethical principles of medical practice (this is the case for the USA, the UK, the Netherlands); in other countries, however, patients often see truth-telling as an act generating unneeded burden upon them. Again, Pellegrino gave the example of Italy, and also other parts of the world, in which "to thrust the truth or the decision on a patient who expects to be buffered against news of impending death is a gratuitous and harmful misinterpretation of the moral foundations of respect for autonomy". ${ }^{19}$ To decrease the chances of improperly using therapeutic privilege in a clinical environment, various authors proposed decision algorithms for its acceptance. For example, Richard et al suggested physicians ask six questions before potentially using it. If the answer is yes to all, therapeutic privilege can be used. The questions were as follows: 1) Do you plan to transmit "biased" or "altered" information to the patient? (bearing in mind medical uncertainty); 2) Is the decision not to present the facts accurately likely to increase the patient's well-being or prevent suffering? 3) Does the benefit of transmitting "biased" or "altered" information surpass the detrimental consequences of denying a patient's right to know the "truth"? 4) Is there any other possible course of action that would have greater respect for the patient's right to know? 5) Do you know what the patient's point of view is about the importance of the information you want to hide or alter? 6) Would you be prepared to defend your decision publicly? ${ }^{20}$ Our opinion is that, based on this algorithm at least, the therapeutic privilege cannot be imposed for nosocomial infections. Knowledge about them can significantly alter the decision-making process of patients and can lead to a proactive measure aimed to decrease HAI risk, making the answer to question 5 a definite no.

Nonmaleficence imposes an obligation not to generate any harm to the patients. ${ }^{21}$ Some authors argued that disclosing information about nosocomial infections could produce a significant stress, which could be equated to a breach of nonmaleficence, as it might generate significant interventionrelated anxiety or even therapeutic abandonment. ${ }^{22}$ If this is the case, we could consider disclosing the information as generating maleficence, and we should analyze whether the breach of this principle is allowable in this circumstance since there are other conflicting principles that could potentially supersede it. In the case of HAIs, there are three essential principles that potentially require a different modus operandi: autonomy, ${ }^{21}$ veracity, ${ }^{21}$ and the precautionary principle. ${ }^{11}$ In recent years, various international organizations have started to argue for a more active role of patients and their families in various tasks aimed to improve the quality of the medical act. By taking an active role, patients tend to have better adherence to treatment, have an improved safety after surgery, and have a more open communication with health care workers. ${ }^{23}$ McGuckin et al found that knowledge about HAI could generate specific requirements for health professionals, which might decrease the risk of HAIs. For example, when asked about hand hygiene practices, about $80 \%$ of the responders said they would ask the health care professionals to wash their hands correctly if the importance of this procedure was explained to them. ${ }^{24}$ Therefore, they would be actively involved in detecting improper HAI decreasing procedures and try to correct them. Another study by McGuking et al showed that when actively involving the patients, by asking them to question the hand hygiene to health care workers, soap or gel usage per bed increased by an average of $50 \%$, especially in the surgical wards. ${ }^{25}$ However, this procedure is sometimes ineffective unless the patients are motivated to make these specific verifications. Lent et al found that patients are more involved in performing these requirements if they can provide positive reinforcements (such as thanking health care personnel for washing their hands) or if they have visual reminders. ${ }^{26}$ Seale et al showed that patients often felt embarrassed, intimidated, or shy about asking health care workers (especially senior staff or those of a different gender) about various hygiene procedures not respected by them (such 
as washing the hands, or not covering the mouth and nose while coughing). ${ }^{7}$ Various authors showed that patients were more comfortable asking about hand washing after watching a video. ${ }^{27-29}$ Others found that booklets could augment the involvement of patients in preventive HAI tasks. ${ }^{30,31}$ Therefore, even if, in specific circumstances, information about HAI could cause maleficence, in general, this is not the case; moreover, it aids in the therapeutic management of the patient by adding additional tasks for patients within their relationship with the physicians, which increases the trust in physicians and therapeutic compliance.

The precautionary principle justifies "anticipatory preventive action despite incomplete scientific evidence" ${ }^{10}$ and is usually analyzed within the framework of infectious diseases with the concept of Contact Precautions. Contact Precautions includes a series of tasks aimed mainly to decrease the risk of transmitting diseases from the affected patient, rather than to protect the patient him/herself, such as patient isolation, the use of personal protective equipment by health care workers in contact with him/her, and alerts about this status in medical records. ${ }^{11}$ However, in infectious diseases, this principle has much broader applications. For example, one facet of this principle states that a lack of scientific proof should not be used as an excuse for not taking reasonable measures to minimize a significant threat. ${ }^{32}$ As seen above, there are some studies suggesting that disclosure about HAIs could potentially lead to a patient taking proactive measures for minimizing these risks (such as requiring health care workers to respect preventive HAI procedures). Within this framework, complete disclosure about HAI, including not only the infectious risks associated with various medical procedures, but also the inherent risk of acquiring HAI from the hospital environment, and the needed preventive measures can be seen as an anticipatory preventive action, superseding any potential maleficence generated by disclosure in special groups of patients.

The principle of double effect considers that it is sometimes justified to harm certain individuals for the greater good. ${ }^{7,10,11,33}$ In order to be applicable, it must fulfill four conditions simultaneously: 1) the action should be good or at least morally indifferent; 2 ) the bad should be a possibility, not a certainty; 3 ) the benefit should not be generated by the harmful effect; and 4) there has to be a proportionality between the good and the bad effect. ${ }^{10,34}$ Disclosure about HAI in cases in which the patients seem not to wish to know about the disease (or preventive measures) could be considered a typical example of this principle: 1) the action to tell the truth (veracity) is morally right; 2 ) the bad (adverse consequences for the patient) is a possibility, not a certainty, 3 ) the benefit is generated by truth-telling, not by its negative, potential consequences; and 4) veracity generates certain good effects (social justice, respect for autonomy) and possible adverse effects (increased anxiety, depression, decreased therapeutic compliance).

\section{Practical framework for disclosure} Should information about HAl be disclosed?

Disclosure of medical information is essential within most contemporary models of the physician-patient relationship, as it is a major step in respecting the autonomy of the patient. Disclosure should include all relevant information needed for the patient to make an informed decision about his/her diagnosis and therapeutic management. The relevancy of information is mainly based on his/her capacity to alter the decision-making process of the patient (the information is considered material for the decision process). There are often patients, especially in countries in which HAI-associated mortality is high, who base their decision of selecting a particular medical institution on the overall cleanliness of the facilities and the risk of acquiring HAIs. ${ }^{22}$ McGuckin et al found that $93 \%$ of patients would be influenced by the HAI rate when selecting a health care facility, especially among the patients with a lower income. ${ }^{24}$

As HAI-related information can significantly alter both the decision-making process regarding a specific medical procedure and the decision of being admitted in a particular medical institution, it should be considered material information and should be disclosed to every patient coming to a health care facility for the procedures associated with an above-minimal risk for nosocomial infection or those needing a longer admission.

\section{When should the information about HAI be disclosed?}

Many HAIs are associated with invasive procedures, such as surgery, insertion of catheters, and ventilators. ${ }^{35,36}$ However, the contamination may occur before the procedures. For example, methicillin-resistant Staphylococcus aureus or vancomycin-resistant enterococcus can survive for weeks on environmental surfaces within health care institutions; these surfaces can be touched not only by patients, but also by health care personnel, or visitors, who can transmit the infectious agents anytime to patients. ${ }^{37}$ Hospital staff can transfer various microbial agents from patient to patient; for example, a study by Pittet et al showed, using multivariate analysis of covariate model or predictors of bacterial contamination of the hands 
of gloveless hospital staff, that no hand antiseptic increases bacterial colonies to 52 (95\% CI: 7-98), direct patient contact to 20 (95\% CI: $14-25)$, rupture in the sequence of care to 15 (95\% CI: 7-24), respiratory care to 20 (95\% CI: 7-32), or handling body fluid secretions to $14(95 \% \mathrm{CI}: 1-26) .{ }^{38}$ Sometimes, procedures or treatments done to other patients in the ward may lead to an increased risk for HAIs. A recent study showed that ward-level antibiotic prescribing to inpatients is associated with a statistically increased risk of $C$. difficile infection in that ward, including in patients who did not receive antibiotics. ${ }^{39}$ The duration of admission before surgery directly correlates with the risk of acquiring HAIs. ${ }^{40,41}$ A lack of knowledge about these issues would potentially increase the risk of acquiring HAIs by patients, and therefore, this information should be considered material and brought to their attention at the admission. Proper information regarding where various microbial agents can be found, how they are transmitted, and what are the consequences of their presence could potentially lead to a decrease in morbidity or even mortality.

\section{How should the information be disclosed?}

To support the participatory role of patients in preventing HAIs, health care workers have fundamental roles, both through proper information about preventive measures and through effective measures aimed at engaging the patients in performing preventive measures. The first step, however, is for health care workers to acknowledge that patients can and should have an active role in HAI prevention, ${ }^{33}$ which is often a difficult task. Rawson et al found that health care workers tend to completely control the management of patients with HAIs, by taking unilateral decisions about the use of specific antimicrobial agents (name, duration of treatment, plans about potential escalation/de-escalation of the therapy) or neglecting to present information about the infection and treatment accurately. ${ }^{42}$ This causes anxiety, disempowerment, and frustration with the medical act, ${ }^{42}$ potentially causing a decrease in the trust for the physicians and adherence to medical therapies.

An incorrect information from physicians often leads patients to seek it from somewhere else, often through online searches, which can lead them to obtaining a lower quality information ${ }^{42}$ or information not specifically tailored for them. ${ }^{42}$

Disclosure of medical information by health care workers to hospitalized patients is generally of three main types - general, intervention-related, and needed for spread prevention (Table 1 gives the specific elements that have to be disclosed for each type). The first category is general information, given to the patient during admission, and intervention-specific information, included in the algorithm for signing the IC. The general information contains data about general rules and regulations within the hospital (such as no smoking policy and visiting hours), data about the service providers (both physicians and the health care facility), financial information, and so on. As seen above, the risk for nosocomial infections can be either increased or decreased through various actions performed before a specific medical intervention. Therefore, we consider that it is essential for patients to receive proper information about HAI (especially regarding preventive

Table I HAl-related information

\begin{tabular}{|c|c|}
\hline Type of disclosure & Content of disclosure \\
\hline \multirow[t]{8}{*}{ Admission } & What are HAls? \\
\hline & What is the estimated risk of acquiring HAls? \\
\hline & Methods of transmission \\
\hline & Prevention: \\
\hline & Patient dependent: hand washing, limiting visitor-related interactions, personal hygiene, clothing, use of masks (for \\
\hline & airborne infections), and so on \\
\hline & Health care facility related, which are relevant to the patient: use of gloves, masks, sterile equipment, general rules of \\
\hline & behavior within the facilities \\
\hline \multirow[t]{7}{*}{ Intervention related } & What are HAls? \\
\hline & What is the estimated risk of acquiring HAls in that specific procedure? \\
\hline & Methods of transmission \\
\hline & Methods of minimizing the risk: decolonization (e.g., Mupirocin $2 \%$ ointment for nasal decolonization of Staphylococcus \\
\hline & aureus), hair removal, hand hygiene, body temperature, bathing/showering before surgery, wound care after surgery, \\
\hline & and so on \\
\hline & Potential complications generated by HAls \\
\hline \multirow[t]{3}{*}{ Spread prevention } & What is the risk for third parties, which third parties are at risk? \\
\hline & How to minimize the risk: using gloves, nasal masks, movement restriction, treatments/procedures? \\
\hline & What are the consequences of the transmission for the patient and/or third parties? \\
\hline
\end{tabular}

Abbreviation: HAls, hospital-acquired infections. 
measures) at admission. This would decrease the chances of acting improperly and could determine an active role for patients in preventing HAIs by identifying improper behaviors from other patients, health care staff, or visitors. Furthermore, information at admission might be mandatory in hospitals where infection prevention and control is automated via cyber-physical systems in which both patients and health care workers play significant roles. ${ }^{43,44}$ The second type of information is intervention specific, and it aims to allow patients to take material decisions regarding the acceptance of a particular type of medical procedure. Both types of disclosure are mainly generated by the principle of action-based autonomy. The third facet of disclosure, which is characteristic to HAIs, should be represented by accurate information about methods of minimizing the spread of infectious agents from positive patients to other persons from the hospital facility. This information is specialized, and targets issues that are not necessarily material for the patient at admission or when they suffer a specific medical procedure, but is essential for respecting the principles of relational autonomy, social justice, double effect, and nonmaleficence. By knowing this information, the patients can act proactively in decreasing the spread of the HAIs.

\section{Conclusion}

From a theoretical point of view, disclosure of the HAIrelated information should take into account not only the principle of respect for autonomy, but also nonmaleficence, social justice, veracity, the precautionary principle, and the principle of double effect. All these should be analyzed conjointly before providing patients with material data regarding HAIs. Disclosure of material information should be done as soon as possible to allow the initiation of relevant preventive measures. Disclosure should be complete, accurate, and intervention specific.

\section{Acknowledgment}

This work was undertaken as part of the HAI-OPS project funded by the European Union, under the Eurostars program, Project ID: $9831 / 2015$.

\section{Author contributions}

All authors contributed equally toward data analysis, drafting and revising the paper and agree to be accountable for all aspects of the work.

\section{Disclosure}

The authors report no conflicts of interest in this work.

\section{References}

1. Ott E, Saathoff S, Graf K, Schwab F, Chaberny IF. The prevalence of nosocomial and community acquired infections in a university hospital: an observational study. Dtsch Arztebl Int. 2013;110(31-32): 533-540.

2. Gastmeier P, Geffers C. Nosokomiale Infektionen in Deutschland: Wie viele gibt es wirklich? DMW-Deutsche Medizinische Wochenschrift. 2008;133(21):1111-1115.

3. Zingg W, Holmes A, Dettenkofer M, et al; systematic review and evidence-based guidance on organization of hospital infection controlprogrammes (SIGHT) study group. Hospital organisation, management, and structure for prevention of health-care-associated infection: a systematic review and expert consensus. Lancet Infect Dis. 2015;15(2):212-224.

4. Pronovost PJ, Weast B, Bishop K, et al. Senior executive adopt-a-work unit: a model for safety improvement. Jt Comm J Qual Saf. 2004;30(2): $59-68$.

5. Merle V, Van Rossem V, Tavolacci MP, Czernichow P. Knowledge and opinions of surgical patients regarding nosocomial infections. $J$ Hosp Infect. 2005;60(2):169-171.

6. Martínez Morel HR, Nebot Marzal CM, Sánchez Torres S, Ortí Lucas $\mathrm{RM}$. [The risk of nosocomial infections in the informed consent forms] El riesgo de infección nosocomial en los documentos de consentimiento informado. Gac Sanit. 2013;27(4):383. Spanish.

7. Seale H, Travaglia J, Chughtai AA, Phillipson L, Novytska Y, Kaur R. "I don't want to cause any trouble": the attitudes of hospital patients towards patient empowerment strategies to reduce healthcare-acquired infections. J Infect Prev. 2015;16(4):167-173.

8. Merle V, Tavolacci MP, Moreau A, et al. What factors influence healthcare professionals' opinion and attitude regarding information for patients about hospital infection? J Hosp Infect. 2007;66(3): 269-274.

9. Newton JT, Constable D, Senior V. Patients' perceptions of methicillinresistant Staphylococcus aureus and source isolation: a qualitative analysis of source-isolated patients. J Hosp Infect. 2001;48(4): 275-280.

10. Bryan CS, Call TJ, Elliott KC. The ethics of infection control: philosophical frameworks. Infect Control Hosp Epidemiol. 2007;28(9):1077-1084.

11. Harris J, Walsh K, Dodds S. Are contact precautions ethically justifiable in contemporary hospital care? Nurs Ethics. Epub 2017 Jan 1.

12. Kass NE. An ethics framework for public health. Am J Public Health. 2001;91(11):1776-1782.

13. Herwaldt LA. Ethical aspects of infection control. Infect Control Hosp Epidemiol. 1996;17(2):108-113.

14. Hostiuc S. Informed consent [Consimtamantul informat]. Cluj-Napoca: Casa Cartii de Ştiință; 2014.

15. Beauchamp T, Childress J. Principles of Biomedical Ethics. 5th ed. Oxford, UK: Oxford University Press; 2001.

16. Walter JK, Ross LF. Relational autonomy: moving beyond the limits of isolated individualism. Pediatrics. 2014;133(Suppl 1):S16-S23.

17. Tausig M, Selgelid MJ, Subedi S, Subedi J. Taking sociology seriously: a new approach to the bioethical problems of infectious disease. Sociol Health Illn. 2006;28(6):838-849.

18. Azétsop J, Rennie S. Principlism, medical individualism, and health promotion in resource-poor countries: can autonomy-based bioethics promote social justice and population health? Philosophy Ethics Humanit Med. 2010;5(1):1.

19. Pellegrino ED. Is truth telling to the patient a cultural artifact? JAMA. 1992;268(13):1734-1735.

20. Richard C, Lajeunesse Y, Lussier MT. Therapeutic privilege: between the ethics of lying and the practice of truth. $J$ Med Ethics. 2010;36(6):353-357.

21. Beauchamp TL, Childress JF. Principles of Biomedical Ethics. Oxford, UK: Oxford University Press; 2001.

22. Sharp D, Palmore T, Grady C. The ethics of empowering patients as partners in healthcare-associated infection prevention. Infect Control Hosp Epidemiol. 2014;35(3):307-309. 
23. Pittet D, Allegranzi B, Boyce J, Experts World Health Organization World Alliance for Patient Safety First Global Patient Safety Challenge Core Group of Experts. The World Health Organization guidelines on hand hygiene in health care and their consensus recommendations. Infection Control \& Hospital Epidemiology. 2009;30(7):611-622.

24. McGuckin M, Waterman R, Shubin A. Consumer attitudes about health care-acquired infections and hand hygiene. Am J Med Qual. 2006;21(5): 342-346.

25. McGuckin M, Waterman R, Storr IJ, et al. Evaluation of a patient-empowering hand hygiene programme in the UK. J Hosp Infect. 2001;48(3): 222-227.

26. Lent V, Eckstein EC, Cameron AS, Budavich R, Eckstein BC, Donskey CJ. Evaluation of patient participation in a patient empowerment initiative to improve hand hygiene practices in a Veterans Affairs medical center. Am J Infect Control. 2009;37(2):117-120.

27. Anthony R, Miranda F, Mawji Z, Davis R, Lawrence S, Cerimele R. The LVHHN patient safety video: patients as partners in safe care delivery. Jt Comm J Qual Saf. 2003;29(12):640-645.

28. Davis RE, Joshi D, Patel K, Briggs M, Vincent CA. The medical student as a patient: attitudes towards involvement in the quality and safety of health care. J Eval Clin Pract. 2013;19(5):812-818.

29. Naikoba S, Hayward A. The effectiveness of interventions aimed at increasing handwashing in healthcare workers-a systematic review. J Hosp Infect. 2001;47(3):173-180.

30. Schwappach DL, Frank O, Koppenberg J, Müller B, Wasserfallen JB Patients' and healthcare workers' perceptions of a patient safety advisory. Int J Qual Health Care. 2011;23(6):713-720.

31. Schwappach DL, Frank O, Buschmann U, Babst R. Effects of an educational patient safety campaign on patients' safety behaviours and adverse events. J Eval Clin Pract. 2013;19(2):285-291.
32. Resnik DB. The precautionary principle and medical decision making. J Med Philos. 2004;29(3):281-299.

33. Tartari E, Weterings V, Gastmeier P, et al. Patient engagement with surgical site infection prevention: an expert panel perspective. Antimicrob Resist Infect Control. 2017;6(1):45.

34. Mangan JT. An historical analysis of the principle of double effect. Theol Stud. 1949;10(1):41-61.

35. Dancer SJ. Controlling hospital-acquired infection: focus on the role of the environment and new technologies for decontamination. Clin Microbiol Rev. 2014;27(4):665-690.

36. Bocicor I, Dascalu M, Gaczowska A, et al. Wireless Sensor Network based System for the Prevention of Hospital Acquired Infections. arXiv preprint arXiv:170503505. 2017.

37. Boyce JM. Environmental contamination makes an important contribution to hospital infection. J Hosp Infect. 2007;65(Suppl 2):50-54.

38. Pittet D, Dharan S, Touveneau S, Sauvan V, Perneger TV. Bacterial contamination of the hands of hospital staff during routine patient care. Arch Intern Med. 1999;159(8):821-826.

39. Brown K, Valenta K, Fisman D, Simor A, Daneman N. Hospital ward antibiotic prescribing and the risks of Clostridium difficile infection. JAMA Intern Med. 2015;175(4):626-633.

40. Venier AG, Leroyer C, Slekovec C, et al; DYNAPYO study group. Risk factors for Pseudomonas aeruginosa acquisition in intensive care units: a prospective multicentre study. J Hosp Infect. 2014;88(2):103-108.

41. Saunders L, Perennec-Olivier M, Jarno P, et al. Improving prediction of surgical site infection risk with multilevel modeling. PLoS One. 2014;9(5):e95295.

42. Rawson TM, Moore LS, Hernandez B, et al. Patient engagement with infection management in secondary care: a qualitative investigation of current experiences. BMJ Open. 2016;6(10):e011040.
Infection and Drug Resistance

\section{Publish your work in this journal}

Infection and Drug Resistance is an international, peer-reviewed openaccess journal that focuses on the optimal treatment of infection (bacterial, fungal and viral) and the development and institution of preventive strategies to minimize the development and spread of resistance. The journal is specifically concerned with the epidemiology of antibiotic

\section{Dovepress}

resistance and the mechanisms of resistance development and diffusion in both hospitals and the community. The manuscript management system is completely online and includes a very quick and fair peerreview system, which is all easy to use. Visit http://www.dovepress.com/ testimonials.php to read real quotes from published authors. 